\title{
Necrotizing Enterocolitis: Intraluminal Biochemistry in Human Neonates and a Rabbit Model
}

\author{
DAVID A. CLARK, JEFFREY E. THOMPSON, LEONARD B. WEINER, JULIA A. MCMILLAN, \\ ALBERT J. SCHNEIDER, AND JOHN E. ROKAHR
}

Department of Pediatrics, SUNY, Upstate Medical Center, Syracuse, New York

\begin{abstract}
The intestinal contents of 17 neonates with necrotizing enterocolitis were analyzed for $\mathrm{pH}$, carbohydrate, protein, and bacteria. The intraluminal $\mathrm{pH}$ was $<5.0$ (16/17). Sufficient carbohydrate and bacteria capable of fermenting the carbohydrate to organic acids were found. The intraluminal protein content was $>5 \mathrm{~g} / \mathrm{dl}$. The variables of acid and protein were then examined in a rabbit intestinal loop model. The hemorrhagic response in individual loops was measured using $\mathrm{Cr}^{51}$ tagged red blood cells such that the microliters of blood per centimeter intestine could be determined. Loops with organic acid and protein had significantly $(p<0.01)$ more intramural blood than control loops. Organic acid (possibly generated by bacterial mixed acid fermentation of carbohydrate) in the presence of protein promotes intramural hemorrhage similar to that seen in neonates with necrotizing enterocolitis. (Pediatr Res 19: 919-921, 1985)
\end{abstract}

Abbreviation

NS, normal saline

The etiology of necrotizing enterocolitis has remained elusive despite numerous theories. It occurs primarily in infants born prior to $34 \mathrm{wk}$ gestation $(1,2)$. These infants have intestinal ileus, abdominal distention, and bloody stools. Roentgenographic examination of the abdomen reveals distended loops of bowel and in the classic presentation, pneumatosis intestinalis $(1,3)$. Often the clinical course is fulminant with hemorrhagic necrosis of the bowel, metabolic acidosis, respiratory insufficiency, and sepsis progressing to death (4).

While numerous epidemiologic associations have been suggested, only a few consistent underlying factors have been identified. These include prematurity $(1,5)$, enteral feeding $(6,7)$, and enteric bacteria $(3,8)$. Reports have also noted a clustering of cases suggesting an infectious agent, but investigations to define a causative bacteria or virus have as yet been inconclusive $(6,9)$. Numerous investigators have implicated compromised intestinal vascular supply resulting from birth asphyxia, respiratory distress, hypotension, and the use of umbilical arterial catheters. Unfortunately, recent studies have shown that many of these epidemiologic associations cannot be confirmed with careful analysis (10)

Although prevailing theories suggest a primary vascular insult, many preterm infants seem to have an abrupt onset of necrotizing enterocolitis with no obvious predisposing factors. We ex-

Received August 21. 1984: accepted April 24, 1985

Reprints David A. Clark. M.D.. Department of Pediatrics. Westehester County Medical Center. Valhalla. NY 10595. amined the intestinal contents of preterm infants with severe necrotizing enterocolitis. The low intraluminal $\mathrm{pH}$ and high protein content in the intestines of these neonates led us to examine the variables of $\mathrm{pH}$ and protein in a rabbit intestinal loop model.

\section{MATERIALS AND METHODS}

Neonates. We obtained the intestinal contents at or adjacent to the site of perforation or necrosis in 17 infants requiring surgical removal of the intestine for advanced necrotizing enterocolitis. The intestinal contents were analyzed for blood, $\mathrm{pH}$, carbohydrate, protein, and bacteria. The presence of blood was confirmed by the guaiac test. The presence of carbohydrate available for bacterial fermentation was initially determined by reducing substances and then quantitated by measurement of glucose after incubation with lactase (Nutritional Biochemicals). The protein content was determined by the Lowry technique and the primary protein present was estimated by acrylamide gel electrophoresis (11). The contents were cultured for aerobic and anaerobic organisms by routine bacteriologic techniques. The predominant lactose fermenting aerobic organism was isolated on MacConkey media.

Rabbit model. A modification of the rabbit intestinal loop model of Kasai and Burrows provided a means for examining the variables of intraluminal $\mathrm{pH}$ and protein $(12,13)$. Sixteen New Zealand white weanling, 3-wk-old-male rabbits were fasted for $8 \mathrm{~h}$. Blood from a cross-match compatible donor rabbit was drawn by syringe and the red blood cells were labeled with Chromium $^{51}$. A $1-\mathrm{ml}$ aliquot of blood was then injected into each rabbit by ear vein. The rabbit was then anesthetized with Ketamine, and the abdomen was shaved and cleansed for surgery. The peritoneum was opened and a ligature was placed just distal to the ligament of Treitz. The intestine was flushed with $10 \mathrm{ml}$ of warm sterile saline and then ligated into nine $4-5 \mathrm{~cm}$ intestinal loops.

These loops were injected randomly using a 26-gauge needle with $1 \mathrm{ml}$ of each of the following solutions: 1) normal saline; 2) whole purified bovine casein (Pentex) $10 \mathrm{mg} / \mathrm{ml}$ in NS; 3) chymotrypsin (Sigma) $10 \mathrm{mg}$ in NS; 4) hydrochloric acid pH 4.0 in NS; 5) organic acid (propionic acid) $\mathrm{pH} 4.0$ in NS; 6) casein $10 \mathrm{mg}$ with hydrochloric acid pH 4.0 in NS; 7) chymotrypsin 10 $\mathrm{mg}$ with hydrochloric acid pH 4.0 in NS; 8) casein $10 \mathrm{mg}$ in propionic acid pH 4.0 in NS; 9) chymotrypsin $10 \mathrm{mg}$ in propionic acid pH 4.0 in NS.

The peritoneum was closed and the animals were allowed to recover from anesthesia. Eighteen hours later the animals were sacrificed, the intestines were removed, and the length of each loop was measured along its mesenteric border. Each loop was washed to remove intraluminal blood. The radioactivity of $1 \mathrm{ml}$ of blood from each animal and of each of the individual intestinal 
loops was then measured by a $\gamma$ counter. An estimate of the intramural blood in microliters per centimeter of intestine could therefore be determined. The data were analyzed by analysis of variance, where the treatments were fixed and the rabbits were considered a random variable (14).

\section{RESULTS}

Neonates. The birth weights of the infants ranged from 790 to $1790 \mathrm{~g}$. The gestational age range at birth was 26 to $34 \mathrm{wk}$. All infants were appropriate for gestational age. Only two of the 17 infants had birth asphyxia with a 1-min Apgar score of less than three. In each case the 5-min Apgar score was five or greater. Sixteen of the 17 infants received a lactose containing formula prior to the onset of their illness. The remaining newborn was fed both frozen homologous breast milk and a lactose containing formula. The day of presentation ranged from the 4 th to the 25 th day after birth.

The clinical presentation included a bloody stool (17/17), pneumatosis intestinalis, pneumoperitoneum, or portal air (15/ 17), thrombocytopenia (14/17), and severe metabolic acidosis usually with hypotension (16/17). No infant was hypotensive for the 4 days preceding the onset of his illness. In 15 of the 17 newborns the ileum and colon were the only portions of intestine involved. In the remaining two infants the disease was confined to the jejunum. No infant had duodenal, gastric, or esophageal disease. Nine infants survived with a combination of surgical and medical intervention.

Although the intraluminal contents in only nine of the 17 infants were grossly bloody, blood was detected by guaiac testing on each sample. A pH of less than 5 (range $\mathrm{pH} 3.8$ to 4.6) was found in the lumen of 16 of the 17 afflicted infants. The intraluminal $\mathrm{pH}$ of the remaining newborn was 5.1 and this was the only infant in whom substantial amounts of intraluminal carbohydrate could not be found. The protein content in each case was greater than $5 \mathrm{~g} / \mathrm{dl}$. Although many proteins were found by gel electrophoresis, the dietary proteins were present in the greatest concentration. Within the dietary proteins the casein fraction comprised at least $50 \%$ in each newborn. Bacterial cultures of the intestinal contents revealed an aerobic organism from the Enterobacteriaceae group in 16 of the 17 newborns. Three neonates had more than one lactose fermenting aerobic organism in the intestine. Anaerobic organisms were cultured from five of the 17 infants.

Rabbit model. The intramural blood content of intestinal loops with saline or protein in saline did not differ significantly from each other. Similarly, the loops with propionic acid at a $\mathrm{pH}$ of 4.0 in saline had a mean intramural blood content which did not differ from the NS control. The loops with hydrochloric acid $\mathrm{pH} 4.0$ in NS or hydrochloric acid $\mathrm{pH} 4.0$ in combination with casein or chymotrypsin in NS had a mean intramural blood content which was significantly more $(p<0.01)$ than the saline control (Table 1).

A significant increase in intramural blood was found in loops containing protein with organic acid. The mean intramural blood content of loops with chymotrypsin in propionic acid $\mathrm{pH} 4.0$ was $29.6 \mu \mathrm{l} / \mathrm{cm}$ of intestine while the intramural blood found in loops with casein and propionic acid had a mean value of 37.1 $\mu \mathrm{l} / \mathrm{cm}$ of intestine. Histologic examination of intestinal loops from rabbits who had not received Chromium ${ }^{51}$ revealed that the blood was both intravascular and interstitial in the intestinal loops containing protein and organic acid.

\section{DISCUSSION}

A model proposed for the pathogenesis of necrotizing enterocolitis must adequately include the epidemiologic factors that have been reported including prematurity, formula feeding, and the role of the enteric bacteria. It should also help to explain the occasional clustering of cases and the frequent sudden onset of
Table 1. Intramural hemorrhage in response to intraluminal injection*

\begin{tabular}{llc}
\hline Loop content & & $\begin{array}{c}\text { Mean Intramural } \\
\text { Blood } \\
(\mu \text { l blood/cm intestine })\end{array}$ \\
\hline Saline & Casein & 15.4 \\
Protein & Chymotrypsin & 17.2 \\
\multirow{2}{*}{ Acid } & HCl & 14.8 \\
\multirow{5}{*}{ Protein + acid } & Organic acid & $18.4 \dagger$ \\
& Chymotrypsin $+\mathrm{HCl}$ & 16.3 \\
& Casein $+\mathrm{HCl}$ & $18.5 \dagger$ \\
& Chymotrypsin + organic & 18.3 \\
& Casein + organic & $28.3 \ddagger$ \\
\hline
\end{tabular}

$*$ Group SD $($ ANOVA $)=4.0$.

$\dagger p<0.01$ versus saline.

$\ddagger p<0.001$ versus saline, $p<0.01$ versus other experimental loops.

the illness in an otherwise healthy preterm infant with no obvious predisposing factors. The biochemistry and bacteriology of the intestinal lumen of neonates with necrotizing enterocolitis provide substantial clues to the pathogenesis of the disease.

It has been well demonstrated that preterm infants (less than 34 wk gestation) often have insufficient amounts of the disaccharidase, lactase, and therefore malabsorb lactose (15). This carbohydrate can then be fermented by the colonic flora to yield organic acids, carbon dioxide, and hydrogen. An elevated breath hydrogen has been postulated as a risk factor for necrotizing enterocolitis (16). D-Lactate, a nonmetabolized product of intestinal bacterial fermentation of carbohydrate, has recently been found to be elevated in newborns with necrotizing enterocolitis (17).

Neonates receiving exclusively fresh breast milk are colonized predominantly with Lactobacillus (18). Numerous factors in breast milk inhibit the growth of the Gram-negative bacilli and promote the growth of Lactobacillus; these include lactoferrin which binds iron, immunoglobulins, and cellular elements (19). Lactobacillus as it ferments lactose produces primarily lactic acid, which can be readily absorbed from the intestinal tract (20). The Enterobacteriaceae ferment lactose in the mixed acid fermentation pathway, producing not only hydrogen (the gas in the bowel wall with pneumotasis intestinalis) and carbon dioxide but also numerous other organic acids which may not be cleared as readily from the intestinal lumen (21).

A low intraluminal $\mathrm{pH}$ by itself may result in injury to the intestinal wall, but this is generally a $\mathrm{pH}$ of less than 3.0. As hydrogen ions accumulate within the intestinal lumen other compounds present may be affected. The greatest effects are seen with divalent cations and proteins. Many divalent cations are protein bound and as the $\mathrm{pH}$ decreases are disassociated with an increased ionized fraction. Acid accumulation also results in a change in the spatial configurations of proteins leading to an unfolding of the tertiary structure (22). In our rabbits the hemorrhagic response was most marked when the intestinal loop contained protein and organic acid.

We speculate that proteins within the intestine which have had their tertiary structure altered by a lower $\mathrm{pH}$ may be able to trigger a release of vasoactive substances which then alter intestinal microcirculation. Although histamine is a likely available compound which could produce this hemorrhagic response, numerous other compounds including vasoactive intestinal peptide, serotonin, and members of the prostaglandin series may also be involved in this response (23-26).

The intraluminal biochemistry of neonates with necrotizing enterocolitis in combination with the rabbit model suggests a new model for necrotizing enterocolitis (Fig. 1). A carbohydrate (commonly lactose) along with an intraluminal protein, in combination with a bacteria capable of the mixed acid fermentation 
Carbohydrate

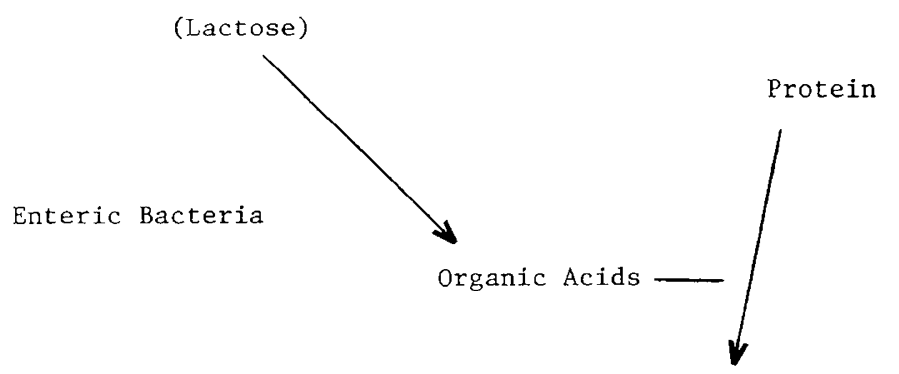

Mucosal Disruption

Enteric Bacteria

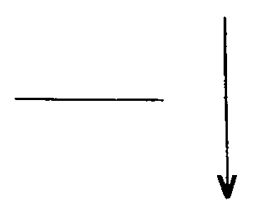

Necrotic Intestine

Fig. 1. Proposed schema of the pathogenesis of necrotizing enterocolitis.

of the carbohydrate, with sufficient time to lower the intestinal $\mathrm{pH}$, could result in release of vasoactive substances leading to mucosal disruption. Bacteria capable of more rapid fermentation of lactose would have a selective growth advantage. They would also generate organic acid more quickly. We speculate that this fermentation capability may be transmitted as a plasmid to another bacteria. An outbreak could conceivably involve several different organisms with their only common ground being their capability to rapidly ferment a carbohydrate. A preterm infant colonized with the same organism would be at less risk for the disease if he were digesting the carbohydrate more completely or if his intestinal absorption of organic acid or intestinal motility were less impaired.

Even the breast-fed infant is not completely free of risk (27). He is more likely to be colonized with Lactobacillus and therefore the generation of acid may be limited. If he were only intermittently breast-fed or fed a combination of formula and breast milk the predominating intestinal flora would likely be the members of the Enterobacteriaceae family (18). Then even the lactose of breast milk in combination with a breast milk or intestinal protein could induce a similar response.

This model does not purport to explain every case of necrotizing enterocolitis. There are certainly newborns with severe asphyxia, cyanotic congenital heart disease, hyperviscosity, severe respiratory distress, or other illnesses with resultant vascular compromise to the intestine. These infants may have infarction and necrosis of any portion of the intestinal tract and it is less commonly isolated to the ileum and colon as it is in the preterm infants who have received some oral nutrition.

The seemingly rapid onset of necrotizing enterocolitis most likely results from our inability to monitor the biochemical events occuring in the intestine where microorganisms and dietary components interact. The susceptibility of the preterm infant to necrotizing enterocolitis may result not only from limited digestive capabilities, but also from his inability to modify adverse intraluminal factors.

Acknowledgments. The authors thank Carol Cristiano and Mary Viola for their secretarial help in the preparation of this manuscript.

\section{REFERENCES}

1. Brown EG, Sweet AY 1982 Neonatal necrotizing enterocolitis. Pediatr Clin North Am 29:1149-1170

2. Wilson R, Kanto WP, McCarthy BJ, Feldman RA 1982 Age at onset of necrotizing enterocolitis. Am J Dis Child 128:186-190

3. Frantz III ID, L'Heureux P, Engel RR, Hunt CE 1975 Necrotizing enterocolitis. J Pediatr 86:259-263

4. O'Neill JA 1981 Neonatal necrotizing enterocolitis. Surg Clin North Arn 61:1013-1022

5. Touloukian RJ 1976 Neonatal necrotizing enterocolitis. Surg Clin North Arn $56: 281-298$

6. Kosloske AM 1979 Necrotizing enterocolitis in the neonate. Surg Gynecol Obstet 148:259-269

7. Krouskop RW 1980 Influence of feeding practices. In: Brown EG, Sweet AY (eds) Neonatal Necrotizing Enterocolitis. Grune-Stratton, New York, pp $57-68$

8. Speer ME, Taber LH, Yow MD, Rudolph AJ, Urteaga J, Waller S 1976 Fulminant neonatal sepsis and necrotizing enterocolitis associated with a nonenteropathogenic strain of Escherichia coli. J Pediatr 89:91-95

9. Virnig NL, Reynolds JW 1974 Epidemiological aspects of neonatal necrotizing enterocolitis. Am J Dis Child 128:186-190

10. Stoll BJ, Kanto WP, Glass RI, Nahmias AJ, Brann AW 1980 Epidemiology of necrotizing enterocolitis: A case control study. J Pediatr 96:447-452

11. Lowry OH, Rosebrough NJ, Farr AL, Randall RJ 1951 Protein measurement with the Folin phenol reagent. J Biol Chem 193:265-275

12. Clark DA, Pelley RP, Schneider AJ 1983 Interaction between bovine casein and V. cholerae enterotoxin in the rabbit ileal loop. Pediatr Res 17:10081012

13. Kasai GJ, Burrows W 1966 The titration of cholera toxin and antitoxin in the rabbit ileal loop. J Infect Dis 116:606-614

14. Steele RG, Torrie JH 1980 Analysis of variance. In: Principles and Procedures of Statistics, 2nd ed. McGraw-Hill, New York, pp 137-167

15. Auricchio S, Rabino A. Murset G 1965 Intestinal glycosidase activities in the human embryo, fetus and newborn. Pediatrics 35:944-954

16. Stevenson DK. Shahin SM, Ostrander CR, Kerner JA, Cohen RS, Hopper AO, Yeager AS 1982 Breath hydrogen in preterm infants: correlation with changes in bacterial colonization of the gastrointestinal tract. J Pediatr 101:607-610

17. Garcia J, Smith FR, Cucinell SA 1984 Urinary D-lactate excretion in infants with necrotizing enterocolitis. J Pediatr 104:268-270

18. Yoshioka H, Iseki K. Fujita K 1983 Development and differences of intestinal flora in the neonatal period in breast-fed and bottle-fed infants. Pediatr 72:317-321

19. Goldman AJ 1973 Host resistance factors in human milk. J Pcdiatr 82:10821090

20. Perlmutter D, Boyle JT, Campos JM, Watkin JB 1982 D-Lactic acidosis, a new metabolic complication of small bowel resection. Pediatr Res 16:173A

21. Stanier RY, Doudoroff M. Adelberg EA 1970 Microbial metabolism: generation and transfer of energy. In: The Microbial World. Prentice Hall, Englewood Cliffs, New Jersey, pp 168-225

22. Ghelis C 1982 Protein Folding. Academic Press, New York, pp 1-160

23. Lake AM, Bloch KJ, Sinclir KJ. Walker WA 1980 Anaphylactic release of intestinal goblet cell mucus. Immunology 39:173-178

24. Lemanske RF, Atkins FM, Metcalfe DD 1983 Gastrointestinal mast cells in health and disease. Part I. J Pediatr 103:177-184

25. Lemanske RF. Atkins FM. Metcalfe DD 1983 Gastrointestinal mast cclls in health and disease. Part II. J Pediatr 103.343-35!

26. Said SI 1983 Vasoactive peptides. Hypertension 5(supp I): I17-I126

27. Kliegman RM. Pittard WB. Fanaroff AA 1979 Necrotizing enterocolitis in nconates fed human milk 95:450-453 